\title{
Comparison of the ontogeny of specific cell surface determinants on normal and delayed implanting mouse embryos
}

\author{
R. L. Klemke and H. M. Weitlauf* \\ Departments of Cell Biology and Anatomy and Obstetrics and Gynecology, Texas Tech University \\ Health Sciences Center, Lubbock, TX 79430, USA
}

\begin{abstract}
The ontogeny of immunospecific cell surface determinants on preimplantation mouse embryos was determined by means of an antibody-dependent complement-mediated cell lysis assay. The determinants conferring sensitivity to lysis in that assay were first observed at the late blastocyst stage on embryos recovered from normal pregnancy on day 5 or grown to an equivalent stage in vitro. Although blastocysts recovered during the dormant phase associated with delayed implantation were not lysed, those recovered following reactivation with an injection of oestrogen to the mother were sensitive. Furthermore, it was found that treating the dormant embryos with neuraminidase rendered them sensitive to lysis. These results demonstrate that the appearance of specific cell surface determinants on mouse embryos is temporally associated with the process of attachment to the uterus in both normal pregnancy and at termination of the dormant phase associated with delayed implantation. They also indicate that those determinants may be 'masked' with sialic acid during embryonic diapause. It is suggested that such cell surface determinants could be important for embryo attachment and that the mechanism responsible for their expression may explain some aspects of the synchronization between the preimplantation conceptus and its mother at the time of implantation.
\end{abstract}

\section{Introduction}

There have been numerous reports in recent years of experiments in which peri-implantation mouse embryos were probed with various antibodies, lectins or charged particles to detect changes in the pattern of expression of cell surface determinants. In some cases changes in expression of particular determinants were found at about the time of implantation and it has been suggested that such factors are involved in attachment of embryos to the uterine epithelium (see Solter and Knowles, 1979; Weitlauf, 1988; and Carson et al., 1990 for reviews). A few investigators have examined the patterns of expression of some of these factors during the dormant and reactivation phases associated with delayed implantation, where it might be expected that the expression of elements that are critical for attachment would be deferred or 'masked' in some way until the signal for implantation is given. Results from these studies indicate that certain of the surface molecules are modulated during delayed implantation including $\mathrm{H} 2$ and non- $\mathrm{H} 2$ antigens (Hakansson and Sundqvist, 1975; Searle et al., 1976; Hathaway and Babiarz, 1988; Hjortberg and Nilsson, 1990), specific carbohydrate moieties (Jenkinson and Searle, 1977; Carollo and Weitlauf, 1981; Chavez and Enders, 1982), and the cell adhesion molecule cell-CAM 105 (Svalander et al., 1987). Such factors then become even stronger candidates for a role in embryo attachment and implantation.

*Reprint requests.

Received 10 November 1992
The experiments reported here were prompted by the observation that mouse blastocysts become sensitive to lysis by certain types of commercially prepared normal rabbit serum containing complement at about the expected time of implantation, whereas those in the dormant phase of delayed implantation do not (Klemke, 1993). The possibility that the surface determinants responsible for this sensitivity are important for embryo attachment and implantation led us to examine their ontogeny. Embryos were recovered at various times during normal implantation and during the dormant and reactivation phases of delayed implantation and tested for expression of the determinants by means of an antibody-dependent complementmediated cytolytic assay. The results indicate that expression of these specific cell surface determinants is temporally associated with embryo attachment and that the mechanism responsible for their appearance may provide synchronization between the conceptus and the mother at the time of implantation.

\section{Materials and Methods}

\section{Collection of preimplantation embryos}

Virgin white Swiss mice (6-8 weeks of age) were placed with males of proven fertility and the finding of a vaginal plug on the following morning confirmed mating (designated day 1 of pregnancy/embryo development). Pregnant animals were housed in rooms with controlled lighting (dark $19.00 \mathrm{~h}$ $06.00 \mathrm{~h}$ ) and were killed by cervical dislocation at various times 

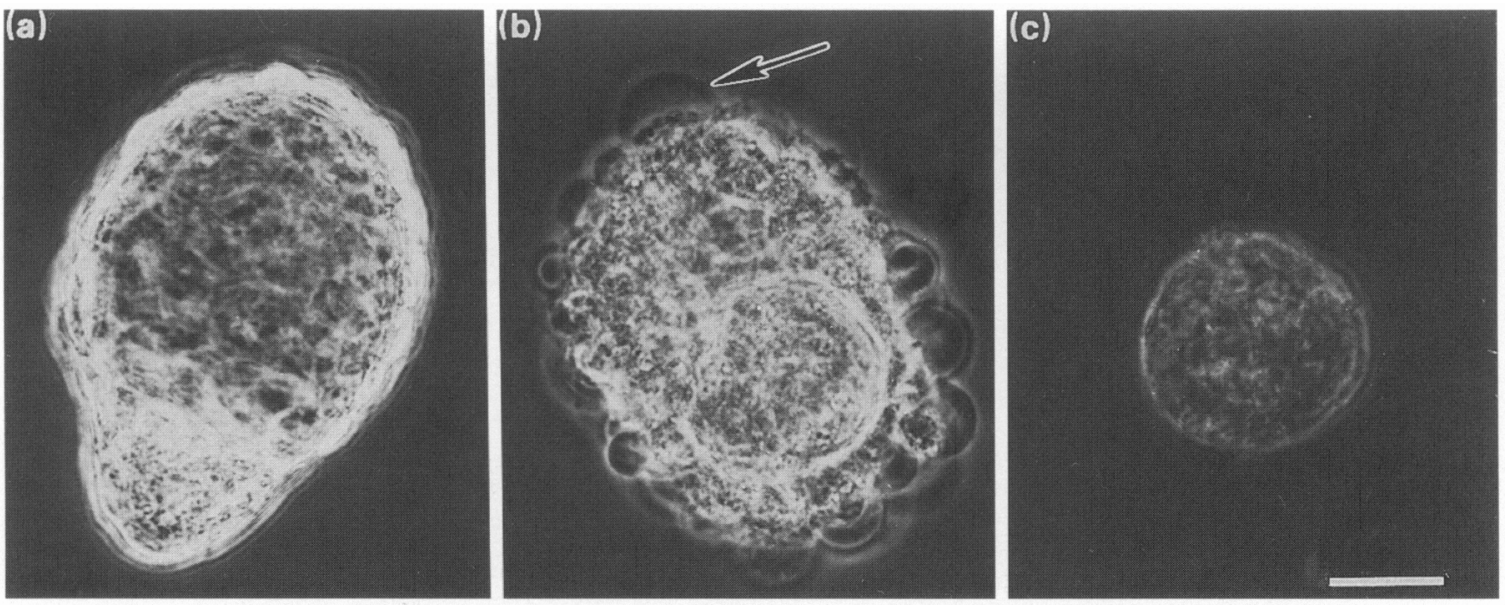

Fig. 1. Phase-contrast photomicrographs of day 5 mouse blastocysts: (a) untreated control; (b) undergoing lysis after being exposed to heat-inactivated normal rabbit serum (NRS) and complement ( $15 \mathrm{~min}$; arrow indicates swollen trophoblast cell); and (c) inner cell mass cleared of lysed trophoblast cells $(60 \mathrm{~min})$. Bar $=20 \mu \mathrm{m}$.

on days 3,4 or 5 ; their reproductive tracts were removed and the embryos recovered by flushing the oviducts (i.e. day 3 ) or uterine horns (i.e. days 4-5) with a stream of tissue culture medium (Dulbecco's modified Eagles' medium, DMEM, Gibco, Grand Island, NY) containing 10\% heat-inactivated fetal bovine serum (FBS, Gibco) from a hypodermic syringe fitted with a blunt needle. Embryos from several animals were pooled, rinsed twice with DMEM-FBS and transferred directly to the various test conditions. In other experiments, blastocysts were recovered from the uteri of animals on various days of the dormant phase of delayed implantation (or during reactivation); treatment of the embryo donor animals consisted of bilateral ovariectomy on day 3 and daily injections of progesterone (i.e. $2.0 \mathrm{mg}$ in $100 \mu \mathrm{l}$ sesame seed oil, s.c.). In some cases reactivated embryos were recovered at times on days 8-9 (i.e. after donors were given an injection of $25 \mathrm{ng}$ oestradiol combined with $2.0 \mathrm{mg}$ progesterone, s.c., on day 8 ; Weitlauf and Greenwald, 1968).

\section{In vitro culture of embryos}

Embryos were recovered on day 3 and incubated (at $37^{\circ} \mathrm{C}$ in $5 \% \mathrm{CO}_{2}$ ) in wells of a Terasaki plate for one or more days before testing (Nunclon, Newbury, CA; i.e. one embryo per well in $10 \mu \mathrm{l}$ of DMEM-FBS). The plates were incubated either upright to allow embryo attachment and outgrowth or inverted (i.e. hanging drops) to prevent attachment and outgrowth (Morris and Potter, 1990).

\section{Antibody-dependent complement-mediated cytolytic test for surface antigens (cytolytic assay)}

The cytolytic assay described by Solter and Knowles (1975) was used with minor modifications. In brief, normal rabbit serum (nonimmune rabbit serum absorbed with mouse spleen and red cells, lot no. 07211, Pel-Freez Clinical Systems, Brown Deer, WI) was heated to $56^{\circ} \mathrm{C}$ for $30 \mathrm{~min}$ to remove endogenous complement activity (NRS) and then used as a source of antibody; guinea-pig serum served as a source of complement (Gibco, lot no. 17K5100). Both NRS and complement were distributed to small vials and stored at $-70^{\circ} \mathrm{C}$. In all experiments, NRS and complement were thawed, diluted to the appropriate concentration with DMEM and used immediately. Conditions for the assay were as follows: 1-15 embryos were preincubated for $60 \mathrm{~min}$ at $37^{\circ} \mathrm{C}$ with $10-50 \mu \mathrm{lNRS}$ at a dilution of $1: 25(\mathrm{v} / \mathrm{v})$. They were then washed twice with DMEM and placed in 10-50 $\mu \mathrm{l}$ of complement at a dilution of $1: 10(\mathrm{v} / \mathrm{v})$ for $60 \mathrm{~min}$ at $37^{\circ} \mathrm{C}$. Typically, within $10 \mathrm{~min}$ of being exposed to complement the trophoblast cells became swollen and began to lyse; trophoblast lysis was essentially complete by 30-45 min. Cell destruction was evaluated using the standard vital dye exclusion method (i.e. trypan blue in PBS, $0.2 \% \mathrm{v} / \mathrm{v}$; Sigma T-8154, St Louis, MO). Embryos were examined and photographed with an inverted Nikon diaphoto microscope with phase contrast optics $(\times 200-400)$. Those embryos with all trophoblast cells lysed at $60 \mathrm{~min}$ were recorded as positive (compare Fig. 1a, b and c). In most cases either all trophoblast cells were lysed or embryos had essentially no stained cells (i.e. $<1 \%$ of the embryos with cells taking up dye exhibited incomplete destruction of the trophectoderm). The results are expressed as the percent lysis (i.e. (number of embryos with all trophoblast cells lysed) $\times$ (total number tested $)^{-1} \times 100$ ). Some embryos were treated similarly except the NRS or complement were omitted as controls. All experiments were done three times with 5-15 embryos from at least five animals. Where linearity of the lytic reaction was determined, regression analysis by the least squares method was used. All values given in the figures are means \pm SEM.

\section{Neuraminidase treatment}

Embryos were preincubated in 10-50 $\mu$ l of DMEM containing $0.2 \mathrm{U}$ neuraminidase $\mathrm{ml}^{-1}$ (Arthrobacter ureafaciens protease-free neuraminidase, one unit hydrolyses $1 \mu \mathrm{mol}$ of $\mathrm{N}$-acetyl-neuraminosyl-D-lactose in $1 \mathrm{~min}$ at $25^{\circ} \mathrm{C}$; Boehringer Mannheim, Indianapolis, IN) for $1.5-2.0 \mathrm{~h}$ at $37^{\circ} \mathrm{C}$. They were 


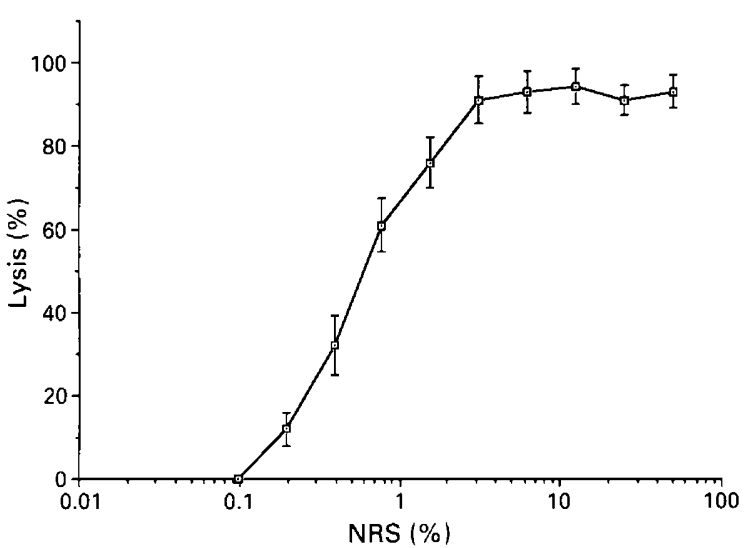

Fig. 2. Proportion of day 5 blastocysts that lyse after being exposed to normal rabbit serum (NRS) followed by complement is linearly related to the concentration of NRS (i.e. between $0.01 \%$ and $3.1 \%[v / v]$, $y=61.9+64.0^{*} \log$ NRS $\%,\left[r^{2}=0.98[)\right.$. Ordinate $(\%$ lysis $)=$ number of embryos lysed $\times$ (number of embryos tested) ${ }^{-1} \times 100$; abscissa $(\%$ NRS $)=($ volume NRS $) \times$ (volume Dulbecco's modified Eagles Medium (DMEM) $)^{-1} \times 100$.

then rinsed twice with DMEM-FBS and subjected to the cytolytic assay described above. Control embryos were treated similarly except: (i) the neuraminidase was inactivated by preheating $\left(65^{\circ} \mathrm{C}\right.$ for $60 \mathrm{~min}$; Uchida et al., 1979); or (ii) the NRS or complement was omitted.

\section{Immunoglobulin concentration}

The radial immunodiffusion assay described by Mancini $e t a l$. (1965) was used with minor modifications to estimate the concentrations of immunoglobulins (IgG and IgM). Briefly, serial dilutions of NRS were added to wells of a $1 \%$ agar plate (i.e. $w / v$ in PBS; PBS-agarose) containing specific antibodies incorporated into the gel: i.e. goat anti-rabbit $\operatorname{IgM}$ ( $\mu$ chain specific, Cappel, West Chester, PA; diluted 1:200 v:v final concentration in PBS-agarose) or goat anti-rabbit IgG $(\gamma$ chain specific, Cappel; diluted 1:200 v:v final concentration in PBSagarose). The NRS was allowed to diffuse for $48 \mathrm{~h}$ and the areas of the radial precipitation rings were converted to concentration by means of a standard curve constructed using known amounts of rabbit IgM (Calbiochem, La Jolla, CA) or rabbit IgG (Cappel).

\section{Results}

Initial experiments were undertaken to characterize the complement-dependent embryo lytic factors present in NRS. The proportion of late blastocyst stage embryos that lysed after exposure to NRS and complement was linearly related to the concentration of NRS (Fig. 2). At concentrations of NRS above $3.0 \%$ there was little or no additional lysis of embryos and, therefore, a concentration of $4.0 \%$ NRS was used in all subsequent experiments. Furthermore, embryos placed in either NRS or complement alone were not lysed even with prolonged exposure. Embryos exposed to NRS and placed in a source of complement that was deficient in component C4 (Quidel, San Diego, CA; see Ellman et al., 1970; Frank et al., 1991) were not
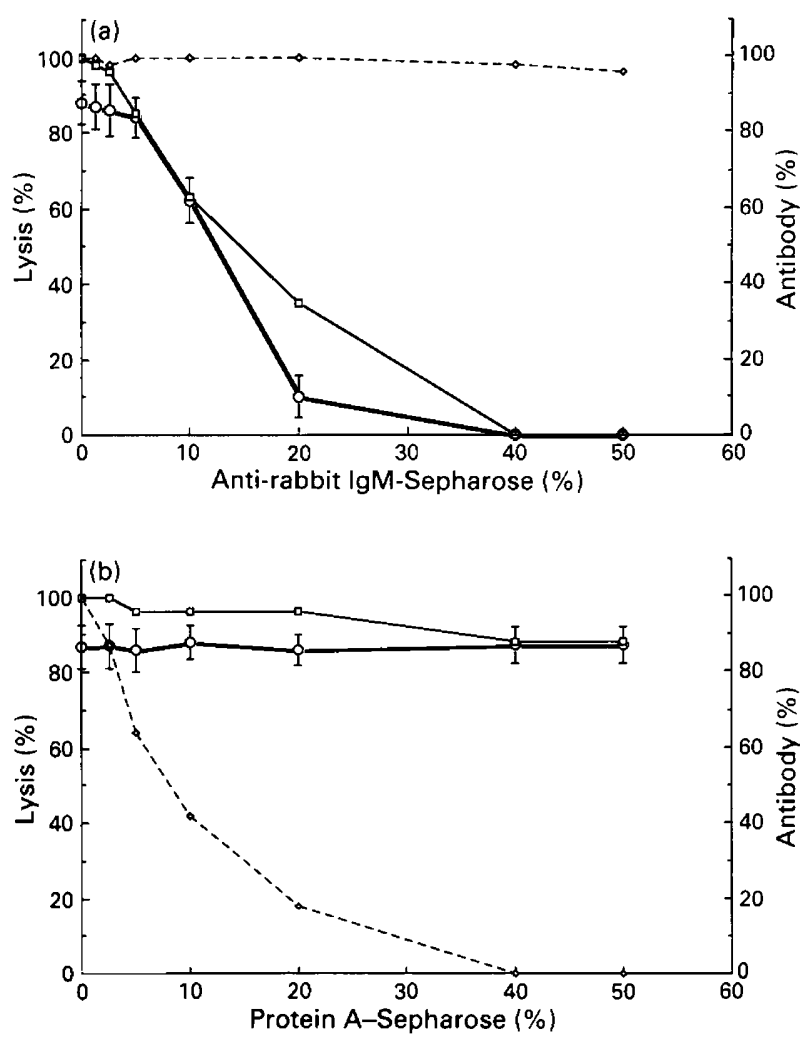

Fig. 3. The association of embryolytic factors in normal rabbit serum (NRS) with immunoglobulins. (a) Increasing the concentration of anti-rabbit IgM-Sepharose (i.e. Sepharose/NRS) reduces the amount of both IgM ( $\square$ ) and lytic activity $(O)$ in NRS while the amount of IgG remains unchanged $(\diamond)$. (b) Increasing the concentration of protein A-Sepharose (i.e. Sepharose/normal rabbit serum (NRS)) reduces the amount of $\operatorname{IgG}(\diamond)$ in NRS but has no effect on either lytic activity (O) or the amount of $\operatorname{IgM}(\square)$.

lysed (i.e. 0 of 43 tested) unless purified C4 (Diamedix, Miami,

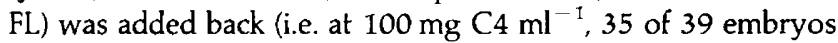
were lysed).

The association of lytic activity with the Ig fraction of NRS was then examined. Lytic activity in NRS was precipitated with Ig by $50 \%$ saturated ammonium sulfate (Stelos, 1967); i.e. 0 of 25 embryos were lysed in the supernatant which contained $6.5 \%$ of the IgG and $0 \%$ of the IgM originally present in NRS, whereas 27 of 32 were lysed in reconstituted precipitate, which contained $88.4 \%$ of the IgG and $97.6 \%$ of the IgM. Lytic activity in the supernatant was also lost when IgM was selectively removed from NRS by precipitation during dialysis with sodium phosphate buffer (2.0 $\mathrm{mmoll}^{-1} ; \mathrm{pH} \mathrm{4.0;} \mathrm{Johnstone} \mathrm{and} \mathrm{Thorpe,} \mathrm{1982);0} \mathrm{of} 27$ embryos were lysed in the supernatant (which contained $90.6 \%$ of the IgG and $0 \%$ of the IgM). Again, lytic activity could be demonstrated in the precipitate in that 25 of 30 embryos were lysed in reconstituted precipitate which contained $7.2 \%$ of the $\operatorname{IgG}$ and $95.2 \%$ of the IgM. Finally, when increasing amounts of $\operatorname{IgM}$ were specifically removed from NRS with increasing amounts of goat anti-rabbit IgM-Sepharose (Harlow and Lane, 1988), a corresponding decrease in lytic activity was observed (Fig. 3a), whereas removing IgG with protein A-Sepharose (Langone, 1982), or treatment with unconjugated Sepharose, did not reduce lytic activity (Fig. 3b). 
Taken together these results suggest that the lysis of trophoblast cells on late stage mouse blastocysts is complement dependent and is mediated by $\operatorname{IgM}$ in the NRS.

\section{Ontogeny of the susceptibility to lysis of embryos developing in vivo}

Embryos, recovered at different stages of development, were tested for susceptibility to lysis by NRS and complement. Those embryos recovered from the reproductive tract before day 5 of normal or delayed implanting pregnancy were not sensitive to lysis (Fig. 4a and b). However, an increasing proportion of those recovered during the course of day 5 of normal pregnancy did become sensitive to lysis (Fig. 4a). In addition, embryos recovered during the dormant phase of delayed implantation (i.e. days 5-10) were not sensitive; but increasing proportions of those recovered at intervals during the $18 \mathrm{~h}$ following a reactivating injection of oestrogen were lysed (Fig. 4b). Interestingly, delaying implanting embryos treated with neuraminidase just before exposure to NRS and complement became sensitive to lysis on day 5 just as in normal pregnancy and they remained sensitive throughout the dormant phase associated with delayed implantation (Fig. 4c).

\section{Ontogeny of the susceptibility to lysis of embryos developing in vitro}

Although embryos recovered on day 3 of pregnancy and cultured for 1 day were not sensitive to lysis (i.e. day 4 equivalent embryos), an increasing proportion of those tested throughout the course of days 5 and 6 were lysed (Fig. 5). Surprisingly, embryos cultured for longer (i.e. tested on days 7-9) became insensitive to lysis; pretreatment with neuraminidase restored sensitivity. These changes were observed with embryos in culture regardless of whether they underwent trophoblast outgrowth or were cultured in hanging drops where outgrowth could not occur.

\section{Discussion}

Results of the experiments reported here demonstrate that stage-specific cell surface determinants are expressed on mouse blastocysts. The determinants are present but apparently 'masked' with sialic acid during the dormant phase associated with delayed implantation and 'unmasked' when the embryos are reactivated following an injection of oestrogen. Because it appears that the mechanism responsible for regulating expression of these determinants comprises a developmentally fixed component and a hormone-responsive variable component, it is suggested that it has the potential for synchronizing interactions between the conceptus and the mother at the time of implantation.

Antibody-dependent complement-mediated cytolytic assays have been widely used for studies of cell surfaces and offer several advantages: (i) the formation of complement pores (i.e. membrane attack complexes) on the plasma membrane requires binding of the antigen recognition portion (i.e. paratope) of a
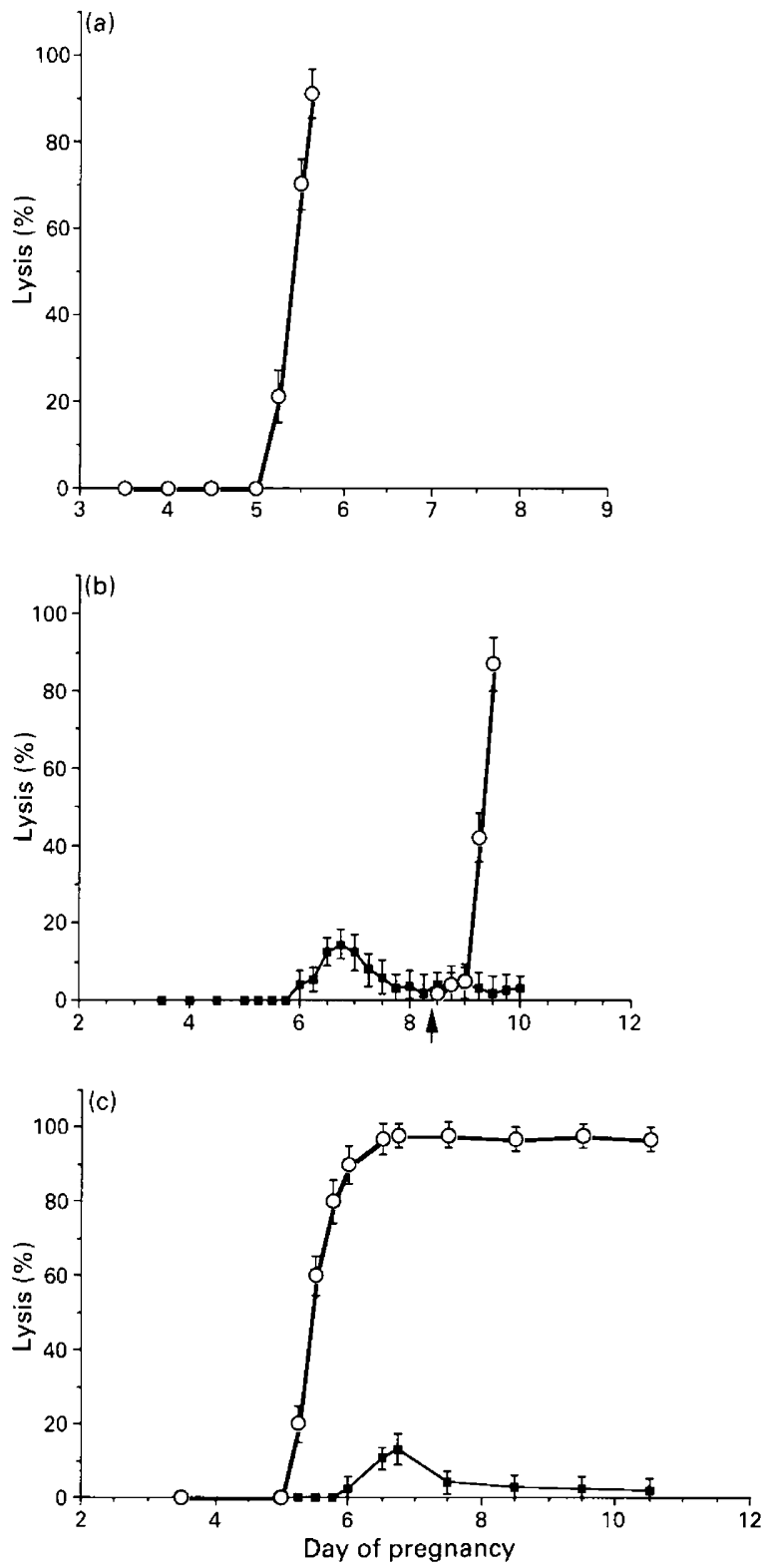

Fig. 4. Ontogeny of the susceptibility to lysis of embryos developing in vivo. (a) Embryos recovered before day 5 of normal pregnancy are not sensitive to lysis by normal rabbit serum (NRS) and complement, whereas an increasing proportion of those recovered during the course of day 5 are lysed. (b) Mouse embryos recovered during the dormant phase associated with delayed implantation ( $\square$ ) are relatively insensitive to lysis by normal rabbit serum (NRS) and complement, whereas those reactivated for implantation (O) following the injection of oestrogen (arrow) develop sensitivity within $18 \mathrm{~h}$. (c) Treatment of delayed implanting embryos with neuraminidase before exposure to normal rabbit serum (NRS) and complement $(O)$ reveals that they become sensitive to lysis on day 5 and remain sensitive throughout the dormant phase; untreated control embryos ( $\square$ ).

complement-fixing antibody to a surface antigen in a specific orientation; (ii) lysis of intact nucleated cells indicates that the antigen is expressed on the cell surface in reasonable numbers; and (iii) a positive result indicates not only that the specific antigen is expressed on the surface but also that it is accessible 


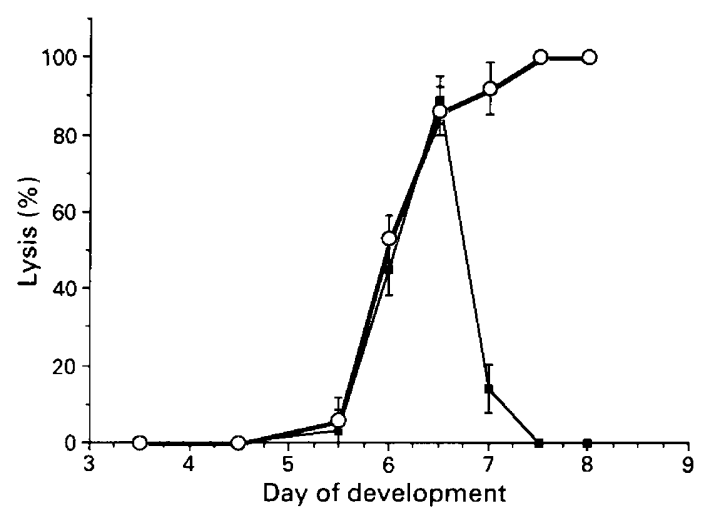

Fig. 5. Ontogeny of the susceptibility of lysis of embryos developing in vitro. Mouse embryos recovered on day 3 of development and cultures in vitro remain insensitive to lysis by normal rabbit serum (NRS) and complement until the late blastocyst stage is reached between day 5 and day 6; sensitivity is lost with culture beyond day 7 (a). By contrast, when cultured embryos are pretreated with neuraminidase before exposure to NRS and complement, they retain their sensitivity to lysis beyond day $7(\mathrm{O})$.

to large extracellular molecules such as pentameric IgM (approximately $900 \mathrm{kDa}$ ) and complement components (approximately $79-410 \mathrm{kDa}$; see Shin and Carney, 1988 for a discussion).

The antibody recognizing the determinants found in the present study is apparently restricted to a particular lot of rabbit serum since sera from other lots either did not lyse mouse embryos at all or did not exhibit a stage-specific pattern. The finding of naturally occurring cytolytic antibodies in various lots of nonimmune serum that recognize specific antigenic determinants has been reported by others and has proven important for studies of blood group antigens, major histocompatability antigens, and tumour associated antigens (see Miller et al., 1989).

Studies directed at identifying cell surface molecules on trophoblast cells from preimplantation embryos have demonstrated the presence of multiple adhesion molecules and that there are changes in a variety of specific carbohydrate moieties and glycoconjugates at about the time of implantation (Solter and Knowles, 1979; Weitlauf, 1988; Carson et al., 1990). It is not known whether any of the various surface molecules observed in these experiments are the same as the determinants found in the study reported here, because different immunological probes and methods of detection have been used. Nevertheless, there are some similarities with the spatiotemporal patterns of expression of a few of the previously reported factors. For example, the antigen recognized by the monoclonal antibody IIC3 (prepared against F9 teratocarcinoma cells) appears on mouse embryos at about the last blastocyst stage (i.e. day 4.5) and disappears from the surface soon after attachment and trophoblastic outgrowth in vitro (Marticorena et al., 1983; Hathaway and Babiarz, 1988). Furthermore, treatment of trophoblastic outgrowths with neuraminidase has been reported to 'unmask' that antigen (Marticorena et al., 1983), although this result could not be confirmed by Hathaway and Babiarz (1988). Similarly, the galactose-containing glycolipid recognized by the monoclonal antibody N63 (IgM) raised to adhesive stage blastocysts (Svalander et al., 1989) and the Mac-2 antigen recognized by a monoclonal antibody $\mathrm{M} 3 / 38$ (IgG) raised to a $32 \mathrm{kDa}$ murine macrophage cell surface glycoprotein (Ho and Springer, 1982; Leenen et al., 1986) are both present on late blastocyst stage mouse embryos (i.e. days 4-5), delayed implanting blastocysts and trophoblastic outgrowths (albeit the antigen identified by N63 is only weakly expressed on trophoblastic outgrowths: Svalander et al., 1989; Weitlauf and Knisley, 1992).

Regardless of the identity of the determinants observed in this study, it is clear that they appear on trophectoderm at about the expected time of implantation whether the embryos develop in vivo or in vitro and that they are 'masked' during the dormant phase of delayed implantation. Although the present results provide no hard data about the functional significance of these surface determinants, or details of the mechanism responsible for their appearance, they do demonstrate that periimplantation embryos have the ability to present and modulate immunospecific cell surface determinants during a narrow developmental 'window'. The mechanism responsible for opening the 'window' is intrinsic to the embryos and results from a developmentally regulated programme that functions in vitro as well as in vivo; it does not appear to be related to the general decrease in surface sialylation that occurs on peri-implantation mouse embryos (Nilsson et al., 1973; Jenkinson and Searle, 1977; Hewitt et al., 1979). A change in glycosylation of surface molecules has been proposed as one mechanism for the appearance and disappearance of stage-specific embryonic antigens (Gooi et al., 1981; Marticorena et al., 1983) and glycosyltransferases and sialidases are present on the surface of mouse embryos and the chorioallantoic membrane (Ada and Lind, 1961; Cook and Ada, 1963; Wudl and Chapman, 1976; Adler et al., 1977; Esworthy and Chapman, 1981; Shur, 1984), but the present results provide no data to implicate specific enzymes in this phenomenon.

It is not yet known whether opening the 'window' is the result of de novo synthesis of the determinants or is due to 'unmasking' by removal of a molecule other than sialic acid. However, closing the 'window' apparently does depend on 'masking' by sialic acid and, again, the mechanism is intrinsic to the embryo since it functions in vitro. Although the present results do not identify the enzymatic activities responsible for changes in 'masking' of the determinants, they do indicate that mouse blastocysts can achieve such changes on their surfaces and that the uterine environment can influence the timing of these changes. Such a mechanism defines a 'window' to some extent and thus has the potential for synchronizing certain aspects of the interaction occurring between the conceptus and the mother at the time of implantation.

This work was supported in part by funds from the NIH (HD 17437) and the TTUHSC Laboratory for the Study of Reproduction; R. L. Klemke was supported by HD 07271. The authors thank M. Y. Hu for technical assistance and K. Knisley for excellent technical advice and valuable discussions.

\section{References}

Ada GL, and Lind PE (1961) Neuraminidase in the chorioallantois of the chick embryo Nature 190 1169-1171 
Adler DA, West JD and Chapman V (1977) Expression of alpha-galactosidase in preimplantation mouse embryos Nature 267 838-839

Carollo JR and Weitlauf HM (1981) Regional changes in the binding of $\left[{ }^{3} \mathrm{H}\right]$ concanavalin $\mathrm{A}$ to mouse blastocysts at implantation: an autoradiographic study Joumal of Experimental Zoology 218 247-251

Carson DD, Wilson OF and Dutt A (1990) Glycoconjugate expression and interactions at the cell surface of mouse uterine epithelial cells and peri-implantation stage embryos. In Trophoblast Invasion and Endometrial Receptivity. Novel Aspects of the Cell Biology of Embryo Implantation pp 211-241 Eds H Denker and JD Aplin. Plenum Press, New York

Chavez DJ and Enders AC (1982) Lectin binding of mouse blastocysts: appearance of Dolichos biflorus binding sites of the trophoblast during delayed implantation and their subsequent disappearance during implantation Biology of Reproduction $26545-552$

Cook B and Ada GL (1963) Neuraminidase in tissues of the chick embryo and chick Biochimica et Biophysica Acta 73 454-461

Ellman L, Green I and Frank MM (1970) Genetically controlled total deficiency of the fourth component of complement in the guinea pig Science 170 74-75

Esworthy S and Chapman V (1981) The expression of beta-galactosidase during preimplantation mouse embryogenesis Developmental Genetics 2 1-12

Frank MM, May J, Gaither T and Ellman L (1971) In vitro studies of complement function in sera of C4-deficient guinea pigs Journal of Experimental Medicine 134 176-187

Gooi HC, Feizi T, Kapadia A, Knowles BB, Solter D and Evans MJ (1981) Stagespecific embryonic antigen involves alpha 1-3 fucosylated type 2 blood group chains Nature 292 156-158

Hakansson S and Sundqvist $K$ (1975) Decreased antigenicity of mouse blastocysts after activation for implantation from experimental delay Transplantation 19 479-484

Harlow E and Lane D (1988) Immunoaffinity purification of antibodies on an anti-immunoglobulin column. In Antibodies: a Laboratory Manual pp 316318 Eds B Hogan, F Costantini and E Lacy. Cold Spring Harbor Laboratory Publications, New York

Hathaway HJ and Babiarz BS (1988) Developmental regulation of the monoclonally defined IIC 3 antigen during primary and secondary trophoblast differentiation in vitro Cell Differentiation 24 55-66

Hewitt K, Beer AE and Grinel F (1979) Disappearance of anionic sites from the surface of the rat endometrial epithelium at the time of blastocyst implantation Biology of Reproduction 21 691-707

Hiortberg M and Nilsson BO (1990) Appearance, shedding and endocytosis of a blastocyst surface galactose-galactosamine derivative detected with a monoclonal antibody. In Trophoblast Invasion and Endometrial Receptivity. Novel Aspects of the Cell Biology of Embryo Implantation pp 179-189 Eds $\mathrm{H}$ Denker and JD Aplin. Plenum Press, New York

Ho MK and Springer TA (1982) Mac-2, a novel $32000 \mathrm{M}_{\mathrm{r}}$ mouse macrophage subpopulation-specific antigen defined by monoclonal antibodies Joumal of Immunology 128 1221-1228

Jenkinson EJ and Searle RF (1977) Cell surface changes on the mouse blastocyst at implantation Experimental Cell Research 106 386-390

Johnstone $A$ and Thorpe $\mathbf{R}$ (1982) Isolation of IgM. In Immunochemistry in Practice pp 56-59 Eds A Johnstone and R Thorpe. Blackwell Scientific Publications, Philadelphia

Klemke RL (1993) Studies of the Expression of a Novel Cell Surface Determinant on Peri-implantafion Mouse Embryos. PhD Thesis, Texas Tech University of Health Sciences Center, Lubbock TX
Langone J (1982) Applications of immobilized protein A in immunochemical techniques Journal of Immunological Methods 55 277-296

Leenen PJ, Jansen A and Van Ewijk W (1986) Murine macrophage cell lines can be ordered in a linear differentiation sequence Differentiation 32 157-164

Mancini G, Carbonara AO and Heremans JF (1965) Immunochemical quantitations of antigens by single radial immunodiffusion Immunochemistry 2 $235-254$

Marticorena P, Hogan B, DiMeo A, Artzt K and Bennett D (1983) Carbohydrate changes in pre- and peri-implantation mouse embryos as detected by a monoclonal antibody Cell Differentiation 12 1-10

Miller V, Chow D and Greenberg A (1989) Natural antibodies. In Natural Immunity pp 172-217 Ed. D Nelson. Academic Press, Australia

Morris JE and Potter SW (1990) An in vitro model for studying interactions between mouse trophoblast and uterine epithelial cells. In Trophoblast Invasion and Endometrial Receptivity. Novel Aspects of the Cell Biology of Embryo Implantation pp 51-69 Eds H Denker and JD Aplin. Plenum Press, New York

Nilsson BO, Lindqvist I and Ronquist G (1973) Decreased surface charge of mouse blastocysts at implantation Experimental Cell Research 106 386-390

Searle RF, Sellens MH, Elson J, Jenkinson J and Billington WD (1976) Detection of alloantigens during preimplantation development and early trophoblast differentiation in the mouse by immunoperoxidase labeling Joumal of Experimental Medicine 143 348-359

Shin ML and Carney DF (1988) Mechanisms of the cellular defense response of nucleated cells to membrane attack by complement. In Cytolytic Lymphocytes and Complement: Effectors of the Immune System (Vol. I) pp 229-249 Eds R Eckhard and M Podack. CRC Press Inc., Boca Raton

Shur BD (1984) The receptor function of galactosyltransferase during cellular interactions Molecular and Cellular Biochemistry 61 143-158

Solter D and Knowles BB (1975) Immunosurgery of mouse blastocyst Proceedings of the National Academy of Sciences USA 72 5099-5102

Solter D and Knowles BB (1979) Developmental stage-specific antigens during mouse embryogenesis. In Current Topics in Developmental Biology pp 139-165 Eds A Moscona and A Monroy. Academic Press, Australia

Stelos P (1967) Isolation of immunoglobulin. In Handbook of Experimental Immunology pp 3-9 Ed. DM Weir. Blackwell Scientific Publications, Philadelphia

Svalander PC, Odin P, Nilsson BO and Obrink B (1987) Trophectoderm surface expression of the cell adhesion molecule cell-CAM 105 on rat blastocysts Development $100653-660$

Svalander PC, Hjortberg M, Gronvik KO and Nilsson BO (1989) Mouse blastocyst surface expression of galactose-containing epitopes coinciding with trophoblast differentiation Cell Differentiation and Development 21 191-200

Uchida Y, Tsukada Y and Sugimori T (1979) Enzymatic properties of neuraminidases from Arthrobacter ureafaciens Joumal of Biochemistry 86 1573-1585

Weitlauf HM (1988) Biology of implantation. In The Physiology of Reproduction pp 231-262 Eds E Knobil and J Neill. Raven Press, New York

Weitlauf HM and Greenwald GS (1968) Influence of estrogen and progesterone on the incorporation of ${ }^{35} \mathrm{~S}$ methionine by blastocysts in ovariectomized mice Journal of Experimental Zoology 169 463-470

Weitlauf HM and Knisley KA (1992) Changes in surface antigens on preimplantation mouse embryos Biology of Reproduction 46 811-816

Wudl L and Chapman V (1976) The expression of beta-glucuronidase during preimplantation development of mouse embryos Developmental Biology $\mathbf{4 8}$ $104-109$ 